\title{
SUBSTRATE USE BY THE WESTERN HOOLOCK GIBBON (HOOLOCK HOOLOCK) IN A SEMIEVERGREEN FOREST OF BANGLADESH
}

\author{
M.K. Hasan 1, M.M. Feeroz, M.A. Islam ${ }^{2}$, M.M. Kabir and Sajeda Begum
}

Department of Zoology, Jahangirnagar University, Savar, Dhaka, Bangladesh; ${ }^{2}$ Department of Zoology, University of Dhaka, Bangladesh Email: ${ }^{1}$ hasan_wildlifeju@yahoo.com

\section{Abstract}

The study was conducted on the substrate height and substrate use by the Western Hoolock Gibbon (Hoolock hoolock) between April 2002 and June 2003 at Lawachara National Park, Bangladesh. One gibbon group with three individuals was followed and a total of 2674 observations were recorded during the study period. Substrate height used by the gibbons ranged between $3 \mathrm{~m}$ and $28 \mathrm{~m}$. They performed most of their activities $(84 \%)$ between $6 \mathrm{~m}$ and $20 \mathrm{~m}$ substrate height. Maximum use of substrate heights in different activities were recorded from $11 \mathrm{~m}$ to $15 \mathrm{~m}$; maximum feeding $(34 \%)$, moving $(40 \%)$, resting $(32 \%)$, calling $(45 \%)$ and social activities $(26 \%)$ were recorded between this $(11 \mathrm{~m} \mathrm{\&} 15 \mathrm{~m})$ heights. Minimum feeding (6\%), moving (5\%) and resting $(6 \%)$ were recorded from $1 \mathrm{~m}$ to $5 \mathrm{~m}$ and minimum calling $(2 \%)$ and social activities $(2 \%)$ were recorded above $26 \mathrm{~m}$ substrate height. In substrate use they performed most of the activities on small branches and near the periphery and least on the trunk of trees. Substrate height and substrate use during different activities varied significantly and between different age-sex classes. Gibbons were not found to perform any activities on the ground.

Keywords

Activities, Bangladesh, height, Hoolock hoolock, Western Hoolock Gibbon, substrate use

The substrate height of primates depend upon the profile of the forest, nature of plant species (total height, bole height, branching system etc.), production and distribution of food at different levels and the site. On the basis of crown size, fruits and figs are distributed at different distances from the trunk of the tree. Since most fruits are found in the periphery of the crown, it is important to know how far a primate can go from the trunk to get its food. Branch diameter becomes smaller with distance from the trunk, so that only smaller animals can be supported (Feeroz \& Islam, 2000). As Lawachara National Park is a semievergreen forest, good number of fruit and fig trees are present here which support a good number of sympatric primates. Sympatric species of this forest coexist without significant competition due to the use of different forest strata, different time allocation for their activities, different size of their home range and day range, their food habits and their preference of substrate height and substrate use (Feeroz, 2000). As Hoolock Gibbons are strictly arboreal, substrate height (vertical space use) and substrate use (horizontal space use) is very important to know the pattern of forest level use and different substrates used by the gibbons during different activities. Studies on substrate height and substrate use during feeding by the Pig-tailed Macaque (Macaca leonina) were conducted by Feeroz (2000) at Lawachara National Park, but there is very little or no information on the substrate height and use by the Hoolock Gibbons, hence the present study.

\section{STUdy Area}

Lawachara National Park in the West Bhanugach reserve forest $\left(24^{\circ} 19.683^{\prime} \mathrm{N} \& 91^{\circ} 47.272^{\prime} \mathrm{E}\right)$ in the Moulvi Bazar forest range of Sylhet forest division currently covers an area of $1,250 \mathrm{ha}$. It is located $7 \mathrm{~km}$ east of Srimangal upazilla. The topography of the area varies from medium to steep hilly slopes. There are many water streams, locally known as Chara and numerous hillocks locally called Tilas, height about 25m-30m. The climate of Lawachara is warm and humid. Humidity ranges from 90 to 95 percent at $0600 \mathrm{hr}$ and 63 to 87 percent at $1800 \mathrm{hr}$. The total annual precipitation is $2000 \mathrm{~mm}$.

This forest is semievergreen type (MacKinnon, 1997) and the majority of the small trees are evergreen and most of the tall trees are deciduous (Ahsan, 1994; Feeroz, 1999). The canopy height varies from 10-30 m. The top canopy comprises of Tectona grandis, Artocarpus chaplasha, Tetrameles sp., Hopea sp. Pygeum sp. and Ficus spp. The second storey consists of Quercus sp., Syzygium sp., Gmelina sp., Dillenia sp. and Ficus spp. The undergrowth includes Bambusa, Geodorum sp. and several ferns and epiphytes. Of the 10 primate species of Bangladesh six are found in Lawachara National Park, i.e. Nycticebus bengalensis, Macaca mulatta, Macaca leonina, Trachypithecus pileatus, Trachypithecus phayrei and Hoolock hoolock. In the park area 11 groups of Hoolock Gibbons containing 37 individuals were recorded (Fig. 3) (Hasan, 2003).

\section{Methods}

Data were collected on one group of Hoolock Gibbons between April 2002 and June 2003 by scan sampling method at 10 minute intervals. Similar method has been used by several scientists, viz., Chivers (1974), Clutton-Brock (1974), Gittins (1982), Islam \& Hussain (1982), Ahsan (1994), Sarker et al. (2005). In that gibbon group there were three individuals; one adult male, one adult female and a juvenile. During scan sampling, the position of the individual was recorded as: (i) the height of the animal above the ground and (ii) distance of the animal from the tree trunk. The first set of data provided the substrate height used by the group and the second set of data provided the different substrates used by the group during different activities. Data were collected from dawn to dusk. A total of 166 hours were spent in the field and 2674 observations were recorded during the study period.

For observing the substrate height and substrate use pattern of gibbon group, substrate height and site of the following major activities were recorded:

Feed: When an individual was actively manipulating a potential food source, putting food into the mouth or masticating;

Manuscript 1590; (C) ZOO; Date of publication 21 May 2007 Received 12 July 2006; Revised received 11 March 2007; Finally accepted 20 February 2007 
when moving and masticating at the same time, they were recorded as feeding, not moving.

Movement: It included directed or non-directed movement from one place to another.

Rest: Included inactive period, when the individuals remained stationary.

Call: Is the loud territorial song, at the time of 10-minutes scan.

Social activities: Social activities included grooming, playing, breeding etc.

A calibrated wide-angle camera lens and in some cases, a $10 \mathrm{~m}$ graded coloured bamboo was used for measuring substrate height used by the group. Substrate height was categorized as: rank-1 (1- $5 \mathrm{~m})$, rank-2 (6-10 m), rank-3 (11-15m), rank-4 (16-20m), rank-5 (21-25m), rank-6 (above 25m) (Martin \& Bateson, 1986; Tomblin \& Cranford, 1994; Feeroz, 2000). Substrate supporting the gibbons were categorized as distance from the trunk (DFT) and thickness of the substrate (TOS). Distances from the trunk were categorized as rank-A (on or near the trunk), rank-B (in between middle of the bough and trunk), rank-C (middle of the branches), rank-D (near the periphery) and rank-E (periphery/end of branches). Thicknesses of the substrate were categorized as rank-1 (trunk) rank-2 (bough), rank-3 (medium branches), rank-4 (small branches) and rank-5 (twigs/very thin branches) (Martin \& Bateson, 1986; Tomblin \& Cranford, 1994; Feeroz, 2000). In each scan the distance and thickness of the substrate used by each individual was recorded by using the distance and thickness ranks (i.e., when an individual was near the periphery of the crown on a medium branch, it was recorded as D/3). Since the food items provided by the vines, lianas and stranglers are found on trees, the height of these was recorded as the height of that tree that supports them. Lianas and vines were not found to be used as substrate during the study period.

\section{Results}

During the study the gibbons used different height of the substrate and this height varied between $3 \mathrm{~m}$ and $28 \mathrm{~m}$. Substrate height used in different activities varied significantly $\left(\chi^{2}=124.774, \mathrm{df}=20, \alpha=5 \%\right)$. They preferred to perform their activities $(83.6 \%)$ between $6 \mathrm{~m}$ and $20 \mathrm{~m}$ substrate height. Maximum feeding (34\%), moving (40\%), resting (32\%), calling $(45 \%)$ and social activities (26\%) were recorded between $11 \mathrm{~m}$ and $15 \mathrm{~m}$ substrate heights. Minimum feeding (6\%), moving $(5 \%)$, resting (6\%) activities were recorded from $1-5 \mathrm{~m}$ and minimum calling $(2 \%)$ and social activities $(2 \%)$ were recorded above $26 \mathrm{~m}$ substrate height. Substrate use in different activities also varied significantly $\left(\chi^{2}=416.69, \mathrm{df}=15, \alpha=\right.$ $5 \%)$. They performed most of the activities on small branches and near the periphery and least on trunk (Table 1). In substrate height use no considerable variation was found among different age sex categories. Male, female and juvenile all mostly used $11 \mathrm{~m}$ to $15 \mathrm{~m}$ substrate height (Fig. 2).

During feeding: The feeding height of the group varied from $3 \mathrm{~m}$ to $26 \mathrm{~m}$, but the group preferred to perform most of their feeding activities ( $84 \%$ ) between $6 \mathrm{~m}$ and $20 \mathrm{~m}$ substrate height (Fig. 1). Maximum feeding observations were recorded from the middle portion of the small branches (12\%) and
Table 1. Different substrate used in different activities (in percentage)

\begin{tabular}{llllll}
\hline $\begin{array}{l}\text { Rank(Distance from } \\
\text { the trunk / Thickness } \\
\text { of the substrate) }\end{array}$ & Feeding & Movement & Rest & Call & Social \\
activities
\end{tabular}

Distance from the trunk: Rank: A - on or near the trunk; B - in between / middle; C - middle of the branches; D - near the periphery; E - periphery / end of branches

Thickness of the substrate: Rank: 1 - trunk; 2 - large branches; 3 - medium branches; 4 - small branches; 5 - twigs / very thin branches

For instance, rank A / 2 means large branches on or near trunk; rank D / 4 means small branches near the periphery.

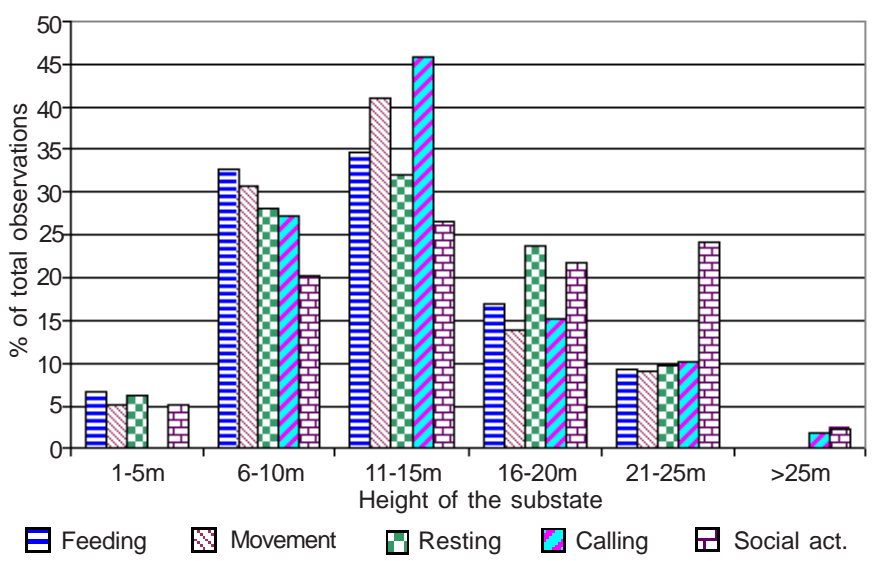

Figure1. Height of the substrate during different activities

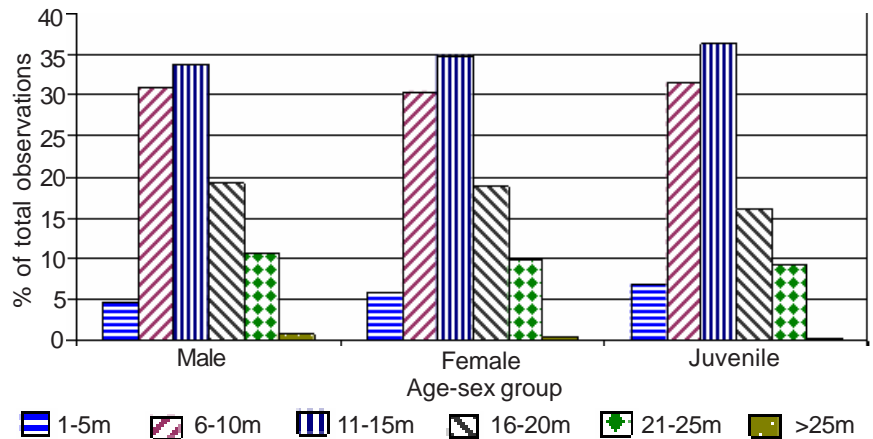

Figure 2. Age-sex variation in substrate height use during different activities 
middle of the medium branches (10\%); and the lowest observations were recorded near the trunk $(1 \%)$ and on the medium branches $(2 \%)$ (Table 1$)$. Substrate used during feeding varied significantly $\left(\chi^{2}=222.45\right.$, df $\left.=15, \alpha=5 \%\right)$.

During movement: Hoolock Gibbons used different canopy height for their movement. They mostly used $6 \mathrm{~m}$ to $20 \mathrm{~m}$ heights for their movement. Maximum movement activity was recorded from $11 \mathrm{~m}$ to $15 \mathrm{~m}(40 \%)$ and the minimum movement was recorded from $1 \mathrm{~m}$ to $5 \mathrm{~m}(5 \%)$. No movement activities were recorded above $25 \mathrm{~m}$ heights (Fig.1). Substrate heights used during moving varied significantly $\left(\chi^{2}=524.60\right.$, df $=5, \alpha=5 \%)$.

Hoolocks mainly used middle portion of the medium and small branches, and near the periphery of the large and medium branches. The highest movement activities were recorded from the middle of the medium branches $(12 \%)$ and middle of the small branches (11\%) and the lowest movement observations were recorded from the periphery of the small branches $(1 \%)$ and middle of the large branches (2\%) (Table 1). Substrate used during moving varied significantly $\left(\chi^{2}=165.445\right.$, df $=$ $15, \alpha=5 \%)$.

During resting: Hoolock Gibbons mostly used 6 to $20 \mathrm{~m}$ heights for resting. The highest resting activity was recorded from 11 to $15 \mathrm{~m}(32 \%)$ and the lowest resting were recorded from the 1 to $5 \mathrm{~m}$ substrate height (6\%) (Fig. 1). Substrate height used during resting varied significantly $\left(\chi^{2}=342.70\right.$, $\mathrm{df}=5, \alpha=5 \%$ ).

For resting hoolocks mainly preferred middle and periphery of the large and medium branches of the tree. Maximum resting activities were recorded from near the trunk of the medium branches (14\%), and near the trunk of the small branches (12\%); and the lowest occurrences were recorded from near the periphery of the small branches (1\%) (Table 1 ). Substrate used during resting varied significantly $\left(\chi^{2}=\right.$ 410.34, df $=15, \alpha=5 \%$ ).

During Calling: Hoolocks generally preferred $6 \mathrm{~m}$ to $20 \mathrm{~m}$ height for calling. Maximum calling activity was recorded from the $11 \mathrm{~m}$ to $15 \mathrm{~m}(45 \%)$ and the lowest occurrence of calling was recorded above $25 \mathrm{~m}$ height (2\%) (Fig. 1). Substrate height used during calling varied significantly $\left(\chi^{2}=106.37\right.$, df $=5$, $\alpha=5 \%)$.

They preferred different thickness of the substrate of large and medium branches. Maximum calling activities were recorded from near the trunk of the large branches (14\%) and middle of the large branches (14\%). The lowest number of observations was recorded from the periphery of the small branches (Table 1). Substrate used during calling varied significantly $\left(\chi^{2}=71.864, \mathrm{df}=15, \alpha=5 \%\right)$.

During social activities: The gibbons generally used $5 \mathrm{~m}$ to $27 \mathrm{~m}$ heights for social activities. The highest social activities were recorded from the $11 \mathrm{~m}$ to $15 \mathrm{~m}$ heights (26\%) and $21 \mathrm{~m}$ to $25 \mathrm{~m}(24 \%)$ and the lowest social activities were at above $25 \mathrm{~m}$ heights $(2 \%)$. Substrate height used during social activities varied significantly $\left(\chi^{2}=55.17, \mathrm{df}=5, \alpha=5 \%\right)$. They used different substrate for social activities. Maximum social activities were recorded from the middle of the medium branches (13\%) and near the trunk of the large branches (12\%); the lowest number of observations was recorded on the small branches, near the periphery (2\%) (Table 1). Substrate used during social activities varied significantly $\left(\chi^{2}=89.904, \mathrm{df}=\right.$ $15, \alpha=5 \%)$.

\section{Discussion}

Food resources vary at different levels of the forest. In the semievergreen forest most fruit is produced in the middle canopy and the frugivore animals prefer to use the middle canopy (Mc Conkey, 1999). In the present study gibbons generally spent most of their time in the middle canopy of the forest (6-20m). The group mostly used 11-15m substrate heights in different activities; that means this canopy level is most suited to perform feeding, moving and other activities. By using this type of canopy level they minimize conflict with other primates, i.e., Macaca mulatta, M. leonina and Trachypithecus pileatus. M. mulatta spend most of their active time on the ground (Feeroz, 2000), but T. pileatus and H. hoolock were not found to use the ground. M. leonina and T. pileatus spend most of their time $(87.5 \% \& 76.2 \%$, respectively) between $5-15 \mathrm{~m}$ substrate heights (Feeroz, 2000) but $H$. hoolock preferred to spend their $83.6 \%$ active time between $6-20 \mathrm{~m}$. T. pileatus is folivorous and they eat most of the young and mature leaves which are distributed throughout the canopy (Feeroz, 2000), while $H$. hoolock eat most of the fruits which are mainly distributed on the small and thin branches near the periphery. Body size and locomotion patterns of primates allow them to use different substrates, which may play an important role in resource partitioning. The brachiation and suspensory locomotion of $H$. hoolock allowed them to spend more time on very thin branches in the periphery of the crown, while relatively large bodied $T$. pileatus spend less time in the periphery (Feeroz, 2000).

$H$. hoolock is territorial and defends its territory by giving loud calls. The group patrol their territory boundary in the early mornings after leaving the sleeping trees (Feeroz, 2000), that's why they prefer large and peripheral trees for calling.

According to Ahsan (1994) the range of substrate height for feeding in gibbons was $4-37 \mathrm{~m}$ at Lawachara but in the present study the feeding height ranged from 3-26 $\mathrm{m}$ and most of the feeding activities were recorded at 6 -20m substrate height. The reason might be that during the last 10-12 years many large trees have been cut down illegally by encroachers, resulting in reduction of canopy height of the forest.

The feeding height of Pig-tailed Macaque varied from 1$28 \mathrm{~m}$ and maximum feeding observations were recorded from 11-13m (Feeroz, 1999), and it varied with the present study. In case of substrate use Pig-tailed Macaques preferred to feed and forage in the middle canopy similar to the gibbons.

In case of Colobus Monkey (Colobus guereza) it was found that they mostly used the medium branches for feeding (Rose, 1984) which is similar with the present study. Brown Capuchin (Cebus appella) mostly used twigs for feeding (47.5\%) while for traveling they mostly used branches $(52.5 \%)$. The Squirrel Monkey (Saimiri sciureus) used bough, branch and twigs for feeding (88.6\%) and for traveling they mostly used branches and twigs. In the present study gibbons preferred medium and small branches for movement, but they avoided twigs. One of the reasons is that small and medium sized branches are 
suitable for their brachiation but the twigs are very fragile and cannot support the body weight. According to Tomblin \& Cranford (1994) Mantled Howlers (Alouatta palliata) spent the majority of their time at the end or the middle of the branches and most frequently positioned themselves on medium-sized branches, which is similar with the gibbons.

Capped Langurs used both thick and thin branches for feeding and they rarely used the trunk as their feeding substrate (Kabir, 2002), which is dissimilar with the gibbons. The reasons may be that gibbons are frugivorous while the langurs are folivorous. Gibbons sometimes used the trunk for feeding figs. In case of Phayre's Langur it was found that they prefer thick branches to the thin branches and they rarely used the trunk as their feeding substrate (Kabir, 2002), which is also dissimilar with the gibbons.

At present Lawachara National Park contains the largest gibbon population of the country, but the gibbon habitat of this forest is been destroyed at an alarming rate. It is hopeful that this study will help in the management of the park and the gibbons.

\section{REFERENCES}

Ahsan, M.F. (1994). Behavioral ecology of the Hoolock Gibbon (Hylobates hoolock) in Bangladesh. Ph.D. Dissertation, University of Cambridge, UK (unpublished).

Chivers, D.J. (1974). The Siamang in Malaya: a field study of a primate in tropical rain-forest. Contributions to Primatology, 4: 1-335, Karger, Basel.

Clutton-Brock, T.H. (1974). Activity patterns of Red Colobus (Colobus badius tephrosceles). Folia Primatologica. 21: 161-187.

Feeroz, M.M. (1999). The Ecology and behaviour of the Pig-tailed Macaque (Macaca nemestrina leonina) in Bangladesh. Ph.D. Dissertation, University of Cambridge, UK (unpublished).

Feeroz, M.M. (2000). Height and substrate use during feeding and foraging by the Pig-tailed Macaque (Macaca nemestrina leonina) in Bangladesh. Journal of Asiatic Society, Bangladesh 26(2): 237-244.

Feeroz, M.M. \& M.A. Islam (2000). Primates of West Bhanugach Forest Reserve: major threats and management plan, pp.239-253. In: Ahmed, M.F. (Ed.). Bangladesh Environment 2000. BAPA, Bangladesh Poribesh Andolon.

Gittins, S.P. (1982). Feeding and ranging in the agile gibbon. Folia Primatologica 38: 39-71.

Hasan, M.K. (2003). Hoolock Gibbon of Bangladesh: Status, Distribution and Ecology, M.Sc. Dissertation, Dept. of Zoology, Jahangirnagar University, Bangladesh (unpublished).

Islam, M.A., \& K.Z. Hussain (1982). A preliminary study on the ecology of the capped langur. Folia Primatologica 39: 145-159.

Kabir, M.M. (2002). Behavioural ecology of two sympatric langur species in the semi-evergreen forest of Bangladesh, Ph.D. Dissertation, University of Cambridge, UK (unpublished).

Martin, P. \& P. Bateson (1986). Recording Methods, pp.48-69. In: Martin, P. \& P. Bateson (Eds.). Measuring Behaviour, Cambridge University Press, New York.

McConkey, K.R. (1999). Gibbons as seed dispersers in the rain forests of central Borneo, Ph.D. Dissertation, University of Cambridge, UK (unpublished).

Rose, M.D. (1984). Food acquisition and the evolution of positional behaviour, pp. 283-301. In: Chiver, D.J., B.A. Wood, A. Bilsborough (Eds.). The Cause of Bipedalism in Food Acquisition and Processing in Primates. Plenum Press, New York.

Sarker, G.C., M.M. Kabir, M.M. Feeroz \& M.K. Hasan (2005). Substrate and height use of Rhesus macaque- Macaca mulatta at Gazipur of Bangladesh. Bangladesh Journal of Life sciences 17(1): 83-92.

Tomblin, D.C. \& J.A. Cranford (1994). Ecological niche differences between Alouatta palliata and Cebus capucinus comparing feeding modes, branch use and diet. Primates 35(3): 357-375.

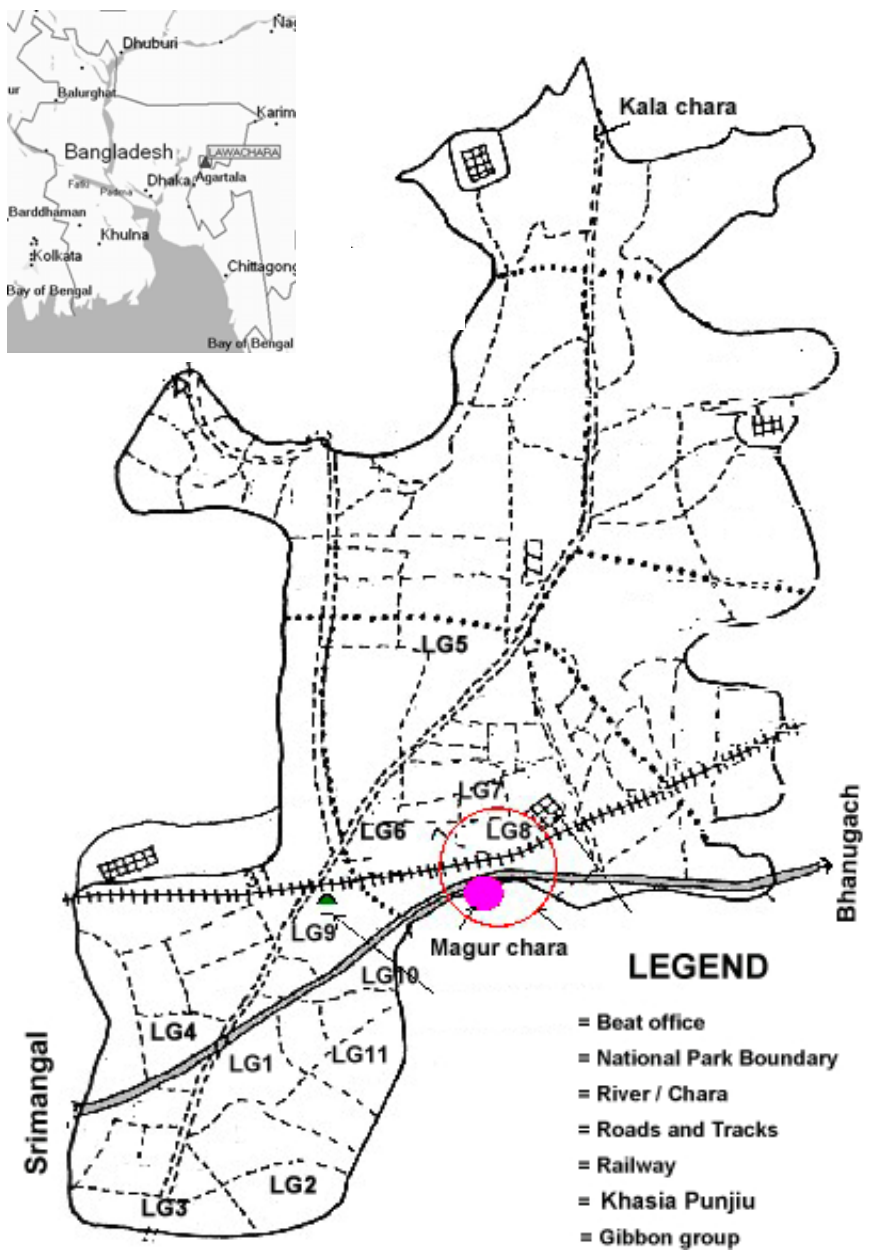

Figure 3. Lawachara National Park 